OPEN ACCESS

Edited by:

Matthias Brand,

University of Duisburg-Essen,

Germany

Reviewed by:

Tagrid Lemenager,

Central Institute of Mental Health,

Germany

Patrick de Zeeuw,

Utrecht University, Netherlands

*Correspondence:

Eunjoo Kang

ekang@kangwon.ac.kr

Specialty section:

This article was submitted

to Psychopathology,

a section of the journal

Frontiers in Psychiatry

Received: 27 June 2017 Accepted: 19 September 2017 Published: 05 October 2017

Citation:

Kim J, Kim H and Kang E (2017) Impaired Feedback Processing for

Symbolic Reward in Individuals with Internet Game Overuse.

Front. Psychiatry 8:195.

doi: 10.3389/fpsyt.2017.00195

\section{Impaired Feedback Processing for Symbolic Reward in Individuals with Internet Game Overuse}

\author{
Jinhee Kim ${ }^{1}$, Hackjin $\mathrm{Kim}^{2}$ and Eunjoo Kang ${ }^{1 *}$ \\ ${ }^{1}$ Department of Psychology, Kangwon National University, Chuncheon, South Korea, ${ }^{2}$ Department of Psychology, Korea \\ University, Seoul, South Korea
}

Reward processing, which plays a critical role in adaptive behavior, is impaired in addiction disorders, which are accompanied by functional abnormalities in brain reward circuits. Internet gaming disorder, like substance addiction, is thought to be associated with impaired reward processing, but little is known about how it affects learning, especially when feedback is conveyed by less-salient motivational events. Here, using both monetary $( \pm 500 \mathrm{KRW})$ and symbolic (Chinese characters "right" or "wrong") rewards and penalties, we investigated whether behavioral performance and feedback-related neural responses are altered in Internet game overuse (IGO) group. Using functional MRI, brain responses for these two types of reward/penalty feedback were compared between young males with problems of IGO (IGOs, $n=18$, mean age $=22.2 \pm 2.0$ years) and age-matched control subjects (Controls, $n=20$, mean age $=21.2 \pm 2.1$ ) during a visuomotor association task where associations were learned between English letters and one of four responses. No group difference was found in adjustment of error responses following the penalty or in brain responses to penalty, for either monetary or symbolic penalties. The IGO individuals, however, were more likely to fail to choose the response previously reinforced by symbolic (but not monetary) reward. A whole brain two-way ANOVA analysis for reward revealed reduced activations in the IGO group in the rostral anterior cingulate cortex/ventromedial prefrontal cortex (vmPFC) in response to both reward types, suggesting impaired reward processing. However, the responses to reward in the inferior parietal region and medial orbitofrontal cortex/vmPFC were affected by the types of reward in the IGO group. Unlike the control group, in the IGO group the reward response was reduced only for symbolic reward, suggesting lower attentional and value processing specific to symbolic reward. Furthermore, the more severe the Internet gaming overuse symptoms in the IGO group, the greater the activations of the ventral striatum for monetary relative to symbolic reward. These findings suggest that IGO is associated with bias toward motivationally salient reward, which would lead to poor goal-directed behavior in everyday life.

Keywords: Internet gaming disorder, feedback learning, reward value, ventromedial prefrontal cortex, ventral striatum 


\section{INTRODUCTION}

Excessive Internet gaming in adolescents and young adults has been a growing public health concern due to its negative psychological and social consequences, including sleep abnormalities, lower well-being, depression, low academic achievement, and job loss [for reviews, see Ref. (1)]. Like pathological gambling disorder, the behavioral and neurological characteristics of this behavioral problem, which is often called Internet gaming disorder (IGD), seem to include the intolerance, craving, and withdrawal symptoms associated with substance abuse (2).

In all addiction, disruption of the dopaminergic mesolimbic system is known to underlie a pathologically persistence that is driven by positive outcomes, despite possible negative consequences $(3,4)$. Just as those with cocaine addiction show distorted sensitivity to positive and negative outcomes $(5,6)$, individuals with IGD also fail to utilize either positive or negative outcome during a guessing task (7-9). Relative to normal healthy individuals, those with IGD also show enhanced activation in the orbitofrontal cortex for positive outcomes and decreased activation in anterior cingulate for negative outcomes (7). Reduced activations were also reported for individuals with IGD in various subcortical regions, depending on reward types (e.g., monetary reward, social reward, and performance feedback) for a simple left/right discrimination task (10).

The dopaminergic mesolimbic system is known to be involved in the experience of hedonic feelings (10), reward prediction (11), and reinforcement learning based on reward-prediction errors (12-14). Increases of neural response have been reported in the ventral striatum (VS) and ventromedial prefrontal cortex (vmPFC) in response to cues associated with addictions, such as nicotine (15) or cocaine (16) addiction. Greater responses in orbitofrontal cortex were also observed in individuals with IGD $(7,17)$ and pathological gambling $(18,19)$, which is in line with the "incentive sensitivity hypothesis" (20). Addiction, however, has also been associated with deficits in the dopaminergic reward system, leading to the "reward deficiency hypothesis" (21) in which problems of substance addiction are viewed as compensatory behavior for deficiencies in the reward system (22). Consistent with this view, IGD individuals showed reduced levels of dopamine $\mathrm{D}_{2}$ receptor availability and dopamine transporter $(23,24)$, as well as reduced striatum activation for cues predicting monetary reward during Internet games $(25,26)$. Both views may explain the poor academic achievement often observed in adolescents and young adults with IGD (27). For example, the selective sensitivity to positive feedback may be related to problems in school or everyday life, where appreciation of reward is based on internal motivation (recognition or awareness of one's progress), not on external incentive (e.g., monetary gain or loss). Alternatively, the deficits in reward processing associated with reduced brain responses may impair feedback processing in learning, including both reward processing for positive outcomes and error processing for negative outcomes.

In human learning, the ability to adjust or maintain one's future behavior involves various cognitive functions, ranging from forming stimulus-response associations based on the repetitive experience of the outcome, to evaluating the value of the outcome itself, to exerting attentional control for remembering the stimulus-response-outcome sequence. The efficiency of feedback processing is often affected by the value of the outcome (such as its saliency), as well as by individual differences in the capacity of attention or memory control. Given that there is a bias in value processing (e.g., overvaluation of game-rewards) in IGD individuals (28), several learning deficits may be predicted for feedback/ reinforcement learning. However, impairments in learning from rewards are not easily separated from those involving penalty, since both reward and penalty serve independently as feedback in reinforcement learning (29). One approach to examining how a deficit or bias in reward processing in IGD influences feedback learning may be to isolate the results of information processing of reward from those of penalty in terms of the rate of behavioral adjustments in future response selection.

In this study, in order to understand the effect of IGD on feedback learning, young male adults at high risk for IGD [i.e., problematic Internet game overuse (IGO)] were examined during a visuomotor association learning task. Identification of the neural mechanisms and behavioral features associated with feedback learning in individuals with IGO should provide further understanding of the reward-related problematic behaviors observed in IGD. We hypothesize that feedback processing during learning would be altered, which, therefore, would result in differences in behavioral performance and neuronal responses in individuals with IGO relative to controls. A primary goal, therefore, was to determine whether and to what extent different types of feedback result in differences in learning and brain responses between IGO individual and controls. In order to separate the effects of reward from penalty feedback on learning, we analyzed the rates of staying with the same response after each reward and the rate of switching to a different choice after penalty. As well as impaired reward processing, abnormal insular and anterior cingulate cortex responses associated with response inhibition or error processing have been reported in IGD individuals $(8,30)$. Thus, it is conceivable that alterations in feedback processing of reward and/or penalty would be reflected in the responses of brain regions related to reward and/or penalty, respectively. In order to assess feedbacks of different motivational saliency, we compared the effects of monetary and symbolic feedback. If IGO is associated with greater bias toward externally salient incentive relative to less-salient ones, we would predict that the effect of saliency on learning would be greater for those with IGO than those without IGO. We would also predict that these differences in feedback saliency would result in different patterns of activation of the reward network between IGO individuals and controls. Of particular interest are the vmPFC, which is known to be involved in evaluation of the subjective value of objects or events (31), and the VS, which has been suggested to encode hedonic experience (32).

In addition to evaluating the hypothesis and related predictions outlined above, we also wished to determine if the severity of IGO symptoms is associated with greater bias in hedonic responses of VS, as was previously found for gambling disorder (19). To achieve this, we examined the relationship between IGO severity measured in questionnaires and the difference in VS responses to monetary relative to symbolic reward. 


\section{MATERIALS AND METHODS}

\section{Participants}

The participants consisted of 18 young males with IGO (IGOs; age $22.2 \pm 2.0$, males) and 20 Control males (Controls; age: $21.2 \pm 2.1$ ), recruited through advertisements in the university community in Kangwon province, South Korea. All were righthanded, and none reported a history of neurological or psychiatric disorders. Written consent was obtained from each participant after the study objectives and methods were fully explained. Participants received the incentives earned during the learning task after finishing the experiment. The study was carried out in accordance with the recommendations of the principles of Declaration of Helsinki, with written informed consent obtained from all subjects. The protocol was approved by the institutional review board of Kangwon National University.

As a part of the recruitment procedures, all volunteers were prescreened with the Internet Game Addiction Diagnostic Scale (IGADS) (33) and asked about their type of Internet usage (e.g., shopping, social networking, or game). Only those who reported gaming as their main use of the Internet and showed high scores on the IGADS (higher than the upper $20 \%$ of the distribution, i.e., 67) were classified as potential participants of the IGO group, while those who reported no Internet game activity and had low IGADS scores (lower than the mean, i.e., 47) were provisionally placed in the Control group of the fMRI study. Then, the modified Korean version of the Young's Internet Addiction Test (IAT) $(34,35)$, which consists of 20 items associated with problematic online Internet use, such as withdrawal and intolerance, was administered for those prescreened for the fMRI study. It is scored on a 100-point scale. A value of 50 or higher has been suggested to indicate occasional or frequent problematic Internet use and one over 80 to indicate significant pathological use (36). In this study, only those who showed a criterion score of 50 or higher on the IAT questionnaire were finally placed in the IGO group. Among the potential members of Controls, those who did not reach the criterion score of 50 for the IAT questionnaire, and were of comparable age to the IGO group, were placed in the final Control group.

To characterize the IGO group, the participants were given a clinical assessment and a personality evaluation relevant to the phenomenon of IGD (37). We assessed depression symptoms with the Beck Depression Inventory (BDI) (38), impulsivity with the Barratt Impulsiveness Scale-11 (BIS-11)-Revised (39), and personality traits (novelty seeking, harm avoidance, reward dependence, and persistence) with the Temperament and Character Inventory (TCI) (40). In addition, working memory (WM) capacity was evaluated with digit span forward and digit span backward using a subtest of the Wechsler Adult Intelligence Scale-IV (41).

\section{Stimuli and fMRI Paradigm}

Participants underwent an fMRI scan session of four runs, for which participants were told to learn S-R associations in a trial and error fashion (Figure 1A). For each letter (learning stimulus), one of four alternative keys (response) was to be pressed. Both monetary and symbolic feedbacks were employed to indicate

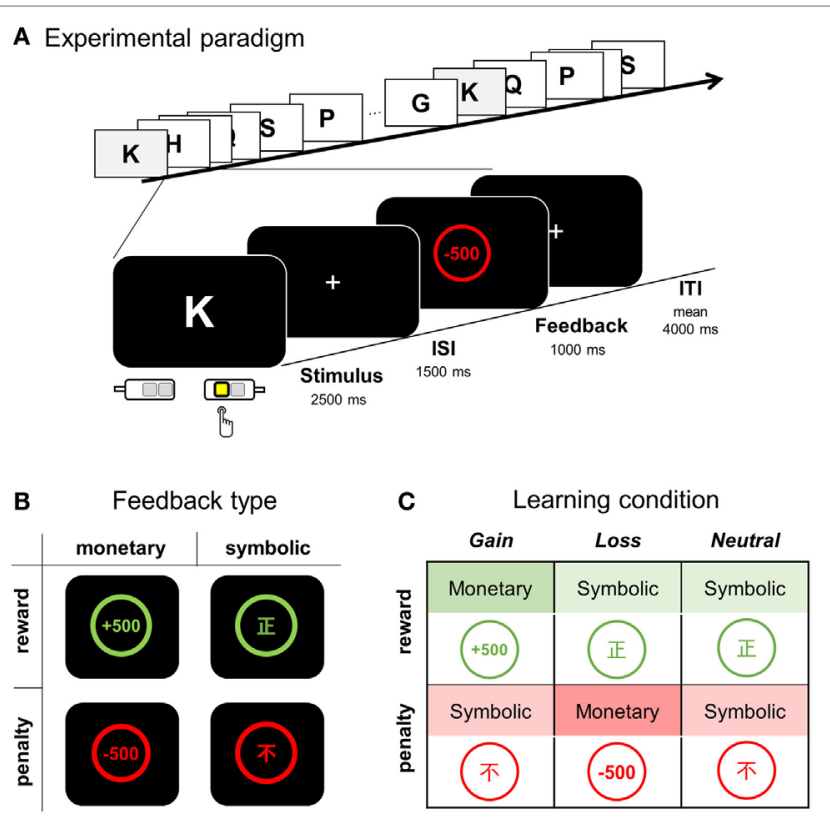

FIGURE 1 | Overview of the feedback type and experimental paradigm. (A) During a visuomotor association task, a participant was instructed to learn appropriate S-R association pairs by pressing one of four response keys while a single letter stimulus was presented for 2,500 ms and followed either by positive or negative feedback for correct and error responses, respectively. (B) Four types of feedback: monetary reward, symbolic reward, monetary penalty, and symbolic penalty. (C) Three types of learning condition according to the feedback contingency. ISI, inter-stimulus interval; ITI, inter-trial interval.

whether the response was correct or an error (Figure 1B). A correct choice was followed by positive feedback, either a monetary gain or via a symbolic signal. Likewise, any erroneous response was followed by negative feedback, either a monetary loss or a symbolic signal. Monetary gain (monetary reward) and loss (monetary penalty) were indicated by “ +500 ” or “ -500 ," respectively, appearing in the center of a circle on the display. The Chinese symbols right [正] (symbolic reward) or wrong [不] (symbolic penalty) appeared in this circle to represent symbolic feedback (educated Koreans are familiar with basic Chinese characters). In order to minimize visual confusion, positive feedbacks were presented in green and negative feedbacks in red.

We compared three learning conditions (i.e., gain, loss, and neutral conditions), each of which differed in the nature of positive and negative feedbacks (Figure 1C). For the association assigned to the gain condition, monetary reward followed a correct response (CR), whereas symbolic penalty followed an error response. For the loss condition, a monetary penalty served as negative feedback, whereas a symbolic reward was used for positive feedback. For the neutral condition, no monetary gain or loss occurred, and only symbolic reward or penalty followed correct and error responses, respectively.

The learning list was composed of 24 English letters; two letters, $\mathrm{O}$ and $\mathrm{X}$ were excluded to avoid associations with pre-existing meanings of correctness (to Koreans, $\mathrm{X}$ is associated with "incorrect" and $\mathrm{O}$ with "correct"). Eight letters were assigned 
to each learning condition, and eight associations ( $2 \times 4$ runs) were to be learned for each learning condition. Only six association pairs (two for each condition) were introduced for each run, during which the associations were repeated eight times (a total of 48 trials per run). Participants were informed that the association contingency between a letter and a target response was fixed for all stimuli and that choosing the CR arbitrarily assigned to each alphabetic character would be always followed by a reward. For each trial, the choice of response was required to be made while a learning stimulus (an English character) was displayed for $2.5 \mathrm{~s}$; feedback was display for $1.0 \mathrm{~s}$, following a 1.5 s inter-stimulus interval (ISI, display of “+”) (Figure 1A). Trials were separated by jittered inter-trial intervals (ITI, display of “+”, mean jitter $=4 \mathrm{~s}$, range $=2.5$ to $6.5 \mathrm{~s}$ ). Responses were made by pressing one of four keys: two keys either with an index or middle finger for each hand. Stimuli and feedback display were presented with an MR-compatible NordicNeurolab Visual system (SVGA, resolution: $800 \times 600$ ), and the behavioral response was recorded using a response button box (4-button box HHSC-2 × 4-c, Current Designs Inc., Philadelphia, PA, USA). Responses faster than $100 \mathrm{~ms}$ were excluded from the analysis of reaction time (RT).

To determine if the valence and arousal for each feedback type differed between two groups, subjective ratings were obtained using a post-experiment questionnaire after the fMRI scan. Emotional valence ("how positive/negative" it was to them: from $1=$ extremely pleasant to $9=$ extremely unpleasant) and arousal ("how relaxing/exciting" it was: from $1=$ not at all aroused to $9=$ extremely aroused) were rated with a self-assessment manikin (42).

\section{MRI Acquisition}

MRI data were collected on a 3-T SIEMENS TRIO scanner with a 12-channel radio frequency coil while participants performed the learning task. T2*-weighted echo planar images were obtained using a gradient echo planar imaging sequence with the following parameters: repetition time $(\mathrm{TR})=2,000 \mathrm{~ms}$, echo time $(\mathrm{TE})=30 \mathrm{~ms}$, flip angle $=90^{\circ}$, slice thickness $=3.0$ with $1 \mathrm{~mm}$ gap, field of view $=240 \mathrm{~mm}^{2}$, matrix size $=80 \times 80$, voxel size $=3.0 \mathrm{~mm} \times 3.0 \mathrm{~mm} \times 3.0 \mathrm{~mm}, 36$ slices, descending sequential, 223 volumes per run. T1-weighted structural data for anatomical localization were acquired using a 3D fast-field echo sequence $\left(\mathrm{TR}=1,900 \mathrm{~ms}, \mathrm{TE}=2.52 \mathrm{~ms}\right.$, flip angle $=9^{\circ}$, field of view $=256 \mathrm{~mm} \times 256 \mathrm{~mm}$, matrix size $=256 \times 256 \times 192$, voxel size $=1.0 \mathrm{~mm} \times 1.0 \mathrm{~mm} \times 1.0 \mathrm{~mm}$ ). Stimulus presentation and behavioral data collection were implemented using E-prime 2.0 software (Psychology Software Tools, Inc., Pittsburgh, PA, USA).

\section{Behavioral Data Analyses}

Conventional behavioral analyses were performed both on the average percentage of CRs and on RT obtained for three conditions of four runs (192 trials), using a two-way mixed ANOVA with two levels of between-subject group factor (IGOs vs. Controls) and three levels of within-subject condition factor (gain, loss, and neutral). Behavioral responses were sorted post hoc, based on the choice of response of the current trial in relationship to the feedback type of the previous trial with the same stimulus. Here we define four types of response: choosing the same response as the one that had been followed by a reward for the previous presentation of the same stimulus (referred to as a "correct-stay response"), or choosing a different response (a "correct-change response"); choosing a different response from the one that had been followed by a penalty for the previous presentation of the same stimulus (an "incorrect-change response"), or choosing the same response (an "incorrect-stay response"). The rate of correctstay (incorrect-change) responses was computed by dividing the total number of correct-stay (incorrect-change) responses by the sum of correct-stay and correct-change responses (incorrect-stay and incorrect-change) responses and subjected to a between group analysis (two sample t-test) for each feedback type. Statistical analyses were performed using IBM SPSS statistics 20.0 (IBM Corp., Armonk, NY, USA), and a threshold for statistical significance of $p<0.05$.

\section{fMRI Data Analyses Image Preprocessing}

Preprocessing and statistical analysis of the fMRI data were performed using Statistical Parametric Mapping software ${ }^{1}$ (SPM12; Wellcome Trust Centre for Neuroimaging, London, UK) implemented in MATLAB R2013b (The MathWorks, Inc., Natick, MA, USA). First, the origin of each individual anatomical image $(x, y$, $z=0,0,0 \mathrm{~mm}$ coordinates) was set to the anterior commissure. Functional data were realigned to the first volume to correct for subject movements, slice-time corrected to the middle of the image acquisition, segmented to white matter, gray matter and CSF using Tissue Probability Map template, spatially transformed to match the MNI template, and spatially smoothed with a 6-mm Gaussian kernel. fMRI data for each individual were high-pass filtered with a cutoff period of 120-s.

Statistical analyses were performed with a two-stage mixed effect model. In the first individual analysis, a general linear model was used to generate voxel-wise statistical parametric maps from the functional data. For each participant, the following regressors were modeled for the four feedback events based on combinations of two feedback valences (positive or negative) and three learning condition trials (gain, loss, or neutral): positive feedback (i.e., monetary reward) and negative feedback (symbolic penalty) for trials of gain condition, positive feedback (symbolic reward) and negative feedback (monetary penalty) at loss condition trials, and positive feedback (symbolic reward) and negative feedback (symbolic penalty) at neutral condition trials, using a stick function time-locked with the presentation of feedback. The regressors were convolved with a canonical hemodynamic response function. Additional regressors of no interest were also included, such as the realignment parameters from the preprocessing step, for correcting for head movement and outlier scans. Outliers based on the global mean signal ( $>5 z$-score) and movement $\left(>2 \mathrm{~mm}\right.$ ) were detected using Artifact Detection Tools $\left(\mathrm{ART}^{2}\right)$. The number of outliers did not differ between groups (IGO: mean $[\mathrm{M}]=18.2, \mathrm{SD}=17.9$; Control: $\mathrm{M}=10.7, \mathrm{SD}=11.9, t=1.53$,

${ }^{1} \mathrm{http}: / /$ www.fil.ion.ucl.ac.uk/spm.

${ }^{2}$ http://www.nitrc.org/projects/artifact_detect. 
$p=0.13$ ). To test whether movements differed between groups, we calculated the mean frame-by-frame movement (43): there are no significant differences between IGO and Control groups (IGO: $\mathrm{M}=0.145, \mathrm{SD}=0.04$; Control: $\mathrm{M}=0.143, \mathrm{SD}=0.06, t=0.12$, $p=0.90)$.

\section{Feedback-Related fMRI Group Analysis}

Individual contrast images for monetary reward, symbolic reward, monetary penalty, and symbolic penalty obtained from the first level analyses were entered to three separated second level group analysis using a random effects model. First, we examined the difference between feedback valence by comparing reward (positive feedback) and penalty (negative feedback). A paired $t$-test was performed with the contrast of $\left[\operatorname{Reward}_{\text {(monetary }+ \text { symbolic) }}\right.$ vs. Penalty (monetary + symbolic) $]$. Brain regions for which significantly greater activations were specific to reward or penalty were used as functional masks for further group analyses. Then a twoway factorial ANOVA was performed to identify brain regions showing a group difference specific to the monetary effect using a between factor (group: IGO vs. Control) and a within factor (feedback type: monetary vs. symbolic). These ANOVAs were separately performed for reward and penalty. Examples of reward analysis follow: the main effect of group using the contrast of $\left[\mathrm{IGO}_{\text {(monetary reward }+ \text { symbolic reward) }}\right.$ vs. Control (monetary reward + symbolic reward) $]$; the main effect of feedback type using the contrast of [monetary $\operatorname{reward}_{(\mathrm{IGO}}+$ Control) vs. symbolic reward $\left.\mathrm{IIGO}_{\text {+ Control })}\right]$; and the interaction of group $\times$ feedback type using the contrast of $\left[\left(\mathrm{IGO}_{\text {monetary reward }}>\mathrm{IGO}_{\text {symbolic reward }}\right)\right.$ vs. (Control monetary reward $_{\text {s }}>$ Control $\left.\left._{\text {symbolic reward }}\right)\right]$. The findings for the main effect of feedback type are listed in Tables S4 and S5 in Supplementary Material for reward and penalty, respectively.

For these whole brain voxel-wise analyses, statistical parametric maps were primarily thresholded at a voxel-level $p$-value of 0.001 and corrected for multiple-comparisons using clusterextent based thresholding, in which a cluster size exceeding $184 \mathrm{~mm}^{3}(k>23)$ was considered significant, which resulting in a cluster-level family-wise error (FWE) corrected $p$-value of 0.05. The cluster-extent estimation was based on a Monte Carlo simulation, using a MATLAB script (cluster_threshold_beta.m obtained from https://www2.bc.edu/sd-slotnick/scripts.htm) with the following parameters: acquisition matrix $=80 \times 80$; original voxel dimensions $=3 \times 3 \times 3$; number of slices $=36$; FWHM $=6$; resampled voxel resolution $=2 \times 2 \times 2$; corrected $p$-value $=0.05 ;$ voxel-based $p$-value $=0.001 ;$ iterations $=1,000$.

From brain regions showing significant responses in the whole brain voxel-wise analyses, the mean percent signal changes were calculated from the first level contrast images for each participant using MarsBar $\left(0.41^{3}\right)$. To reveal patterns of significant interaction, these percent signal changes were also used in simple effect tests using SPSS statistics 20.0. In addition, any possible relationship between the feedback-related brain response and subject's personality, or between the brain response and behavioral measurements, were examined using the Pearson correlation analysis test.

${ }^{3} \mathrm{http}: / /$ marsbar.sourceforge.net.

\section{Correlation Analysis with IGO Symptom Severity for the VS}

Based on our a priori hypothesis for the VS region, we examined the relationship between the incentive-related response of the VS and degree of IGO symptoms, as measured by IAT. The incentive associated brain contrast images (monetary reward $>$ symbolic reward) were subjected to correlation analysis using IAT score as the covariates. Using a small volume correction approach, significance was determined with multiple-comparisons correction (FWE $p$-value of 0.05$)$ within a priori VS mask $(k=384$, volumes $=3,072 \mathrm{~mm}^{3}$ ). The VS mask was made by combining the caudate head ROI (WFU-PickAtlas ${ }^{4}$ with human-atlas TD Brodmann's areas + ) and the nucleus accumbens ROI (HarvardOxford Subcortical Structural Atlas ${ }^{5}$ ). The same analysis was also performed with IGADS score for IGO severity.

\section{RESULTS}

\section{Demographic and Clinical Results}

The demographic, clinical assessment, and personality measurement data were summarized in Table 1. The IGADS, IAT, and game playing time of the IGO group were significantly higher than those of the controls $(t=22.11,12.30,7.66$, respectively, all $p<0.0001)$. There was no group difference in WM capacity $(t=0.13, p=0.90)$. As expected, the IGO group had significantly higher depression (BDI: $t=3.39, p=0.001$ ) and impulsivity scores (BIS-11: $t=4.7, p<0.001$ ), relative to the Control group. We also found IGO-associated group differences in personality traits: higher novelty seeking $(t=2.58, p=0.014)$, harm avoidance $(t=3.55, p=0.001)$, and lower persistence $(t=-3.15, p=0.003)$.

${ }^{4} \mathrm{https} / / /$ www.nitrc.org/projects/wfu_pickatlas.

${ }^{5} \mathrm{http} / / / \mathrm{www} . c m a \cdot m g h . h a r v a r d . e d u /$.

TABLE 1 | Demographic characteristics of participants.

\begin{tabular}{lccrc}
\hline & $\begin{array}{c}\text { IGO } \\
(\boldsymbol{n}=\mathbf{1 8})\end{array}$ & $\begin{array}{c}\text { Controls } \\
(\boldsymbol{n}=\mathbf{2 0})\end{array}$ & $\boldsymbol{t}$ & $\boldsymbol{p}$ \\
\hline Age (years) & $22.17(2.0)$ & $21.20(2.2)$ & 1.40 & $p=0.169$ \\
IGADS & $75.61(6.4)$ & $31.05(6.0)$ & 22.11 & $p<0.001^{\star *}$ \\
IAT & $62.78(10.3)$ & $29.75(5.9)$ & 12.30 & $p<0.001^{\star *}$ \\
Reported time being & $24.06(11.5)$ & $0.91(3.3)$ & 7.66 & $p<0.001^{\star *}$ \\
spent for Game (h) & & & & \\
WM (forward) & $10.7(1.6)$ & $10.6(1.9)$ & 0.13 & $p=0.900$ \\
$\begin{array}{l}\text { Depression (BDI) } \\
\text { Impulsivity (BIS-11) }\end{array}$ & $14.17(8.8)$ & $6.45(4.9)$ & 3.39 & $p=0.001^{*}$ \\
Temperament (TCI) & & & & \\
Novelty seeking & $44.06(6.8)$ & $38.10(7.4)$ & 2.58 & $p=0.014^{*}$ \\
Harm avoidance & $48.50(10.7)$ & $37.30(8.8)$ & 3.55 & $p=0.001^{*}$ \\
Reward dependence & $48.33(8.9)$ & $48.15(12.5)$ & 0.05 & $p=0.959$ \\
Persistence & $39.39(7.4)$ & $48.85(10.6)$ & -3.15 & $p=0.003^{*}$ \\
\hline
\end{tabular}

Mean values are displayed with SDs in parentheses.

IGO group, Internet game overuse group; IGADS, Internet Game Addiction Diagnostic Scale; IAT, Internet addiction test; BDI, Beck depression inventory; BIS-11, Barret Impulsivity Scale-11; TCI, temperament and character inventory, WM, working memory. ${ }^{*}$ Statistical significant at $p<0.05$ (two-tailed).

${ }^{* *} p<0.001$ (two-tailed). 
However, there was no group difference in reward dependence $(t=0.05, p=0.959)$.

\section{Behavioral Results}

\section{Behavioral Effects of Monetary Incentive and Loss}

In general, the $\mathrm{CR}$ rate of the gain condition $(\mathrm{M}=68.7 \%, \mathrm{SD}=7.1)$ was higher relative to the loss $(\mathrm{M}=64.2 \%, \mathrm{SD}=10.7)$ or neutral conditions $(\mathrm{M}=60.4 \%, \mathrm{SD}=13.4)\left[F_{(2,72)}=12.28, p<0.001\right.$, Figure 2A]. The same learning condition effect was observed in RT: shorter RT of the gain condition $(\mathrm{M}=899.9, \mathrm{SD}=175.2 \mathrm{~ms})$ relative to the loss $(\mathrm{M}=972.7, \mathrm{SD}=176.6 \mathrm{~ms})$ or neutral conditions $(\mathrm{M}=985.0, \mathrm{SD}=179.9 \mathrm{~ms})\left[F_{(2,72)}=12.6, p<0.001\right]$. There was no significant difference between the groups (IGO: $\mathrm{M}=62.0 \%$, $\mathrm{SD}=10.8$; Control: $\mathrm{M}=66.6 \%, \mathrm{SD}=6.5)\left[F_{(1,36)}=2.62, p=0.11\right]$ or interaction between group by condition. Like CR, there was no significant group difference in $\mathrm{RT}\left[F_{(1,36)}=1.16, p=0.29\right]$ or interaction between group and condition $\left[F_{(2,72)}=1.85, p=0.16\right]$.

For the correct-stay rate, there was no group difference following monetary reward, $t=-0.57, p=0.57$ (Figure 2B). After symbolic rewards, however, the correct-stay rate of the IGO group $(\mathrm{M}=0.82, \mathrm{SD}=0.18)$ was significantly lower than that of the Control group $(\mathrm{M}=0.91, \mathrm{SD}=0.07), t=-2.17, p=0.036$, indicating a deficit of positive feedback processing in the IGO group only when no incentive was involved. For the incorrect-change rate, no group difference was found either after monetary [IGO: $\mathrm{M}=0.87, \mathrm{SD}=0.09$; Control: $\mathrm{M}=0.86, \mathrm{SD}=0.09, t=0.22$, $p=0.82$ ] or symbolic penalty [IGO: $\mathrm{M}=0.82, \mathrm{SD}=0.12$; Control: $\mathrm{M}=0.85, \mathrm{SD}=0.07, t=-0.94, p=0.35$ ] (Figure 2C). Detailed information for the behavioral results are listed in Table S1 in Supplementary Material.

\section{Individual Differences Associated with Learning Performance}

None of personality or clinical measures was found to be associated with feedback learning performance. However, WM capacity was associated with learning performance in the individuals with IGO. For example, only for the IGO group, both the correct-stay rate following monetary reward $(r=0.57, p=0.013)$ and the incorrect-change rate following monetary penalty $(r=0.62$, $p=0.006)$ were positively correlated with individual WM capacity. Performance following symbolic feedback was not associated with WM capacity for the IGO group (correct-stay rate following symbolic reward: $r=0.38, p=0.13$; incorrect-change rate following symbolic penalty: $r=0.30, p=0.24$ ). For the Control group, no relationship was found with WM capacity for any feedback type (the correct-stay rates following monetary reward, $r=0.05$, $p=0.85$, or symbol reward, $r=0.41, p=0.07$; the incorrectchange rates following monetary penalty, $r=0.14 p=0.56$ or symbol penalty, $r=-0.10, p=0.67$ ).

\section{Subjective Rating of Feedback}

Different valence and arousal ratings for monetary effects (monetary-symbolic) were compared between groups for each feedback valence (Figure S1 and Table S2 in Supplementary Material). Analysis of emotional valence ratings on positive feedback showed that, relative to the Control group, the IGO group exhibited a marginally increased arousal for monetary reward relative to symbolic reward (IGO: $2.11 \pm 2.4$, Control: $0.8 \pm 2.2$, $t=1.75, p=0.09$ ), whereas the two groups did not differ on emotional valence ratings (IGO: $1.78 \pm 1.6$, Control: $1.1 \pm 1.2$, $t=1.47, p=0.15$ ). Interestingly, compared to the Control group, the IGO group rated monetary penalty more negative (IGO: $1.94 \pm 1.6$, Control: $0.85 \pm 1.1, t=2.43, p=0.020)$ and more arousing (IGO: $3.11 \pm 2.3$, Control: $1.3 \pm 1.4, t=2.91 p=0.006$ ) than symbolic penalty.

\section{Imaging Results}

\section{Feedback Valence-Specific Brain Activation: Reward vs. Penalty}

Brain regions showing feedback valence effects are summarized in Table S3 and Figure S2 in Supplementary Material. As expected, various regions (shown in yellow in Figure 3), including vmPFC and VS, showed greater activation for positive relative to negative feedback, while the anterior insula, right DLPFC, and dmPFC, showed greater activations for negative relative to positive feedback. Those valence-specific maps were used for further analysis of group comparison for positive and negative feedback.

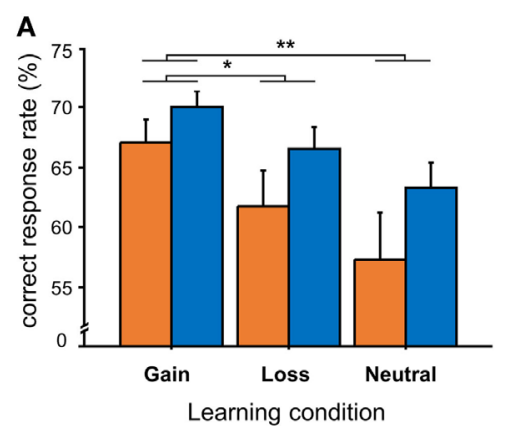

$\square$ IGO group $\square$ Control group
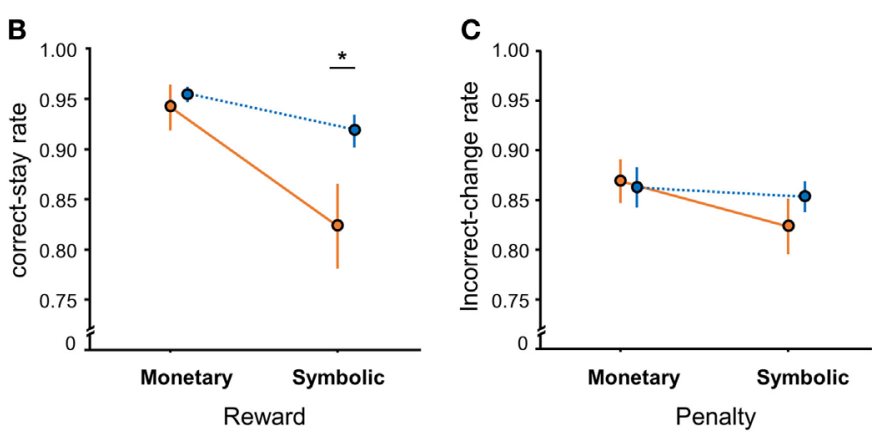

IGO group $\mathrm{O}-$ - Control group

FIGURE 2 | Behavioral results. (A) The mean percent of correct response (CR) in the three learning conditions. (B) The group means of correct-stay rate, i.e., the rate of choosing the same $\mathrm{CR}$, following either monetary or symbolic reward. (C) The group means of incorrect-change rate, i.e., the rate of choosing a different response, following either monetary or symbolic penalty. IGO: Internet game overuse; " $p<0.05, " p<0.01$. 


\section{A $\quad$ IGO $<$ Control group}

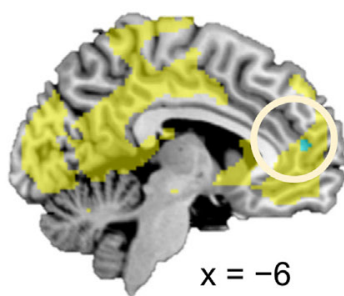

rACC/vmPFC

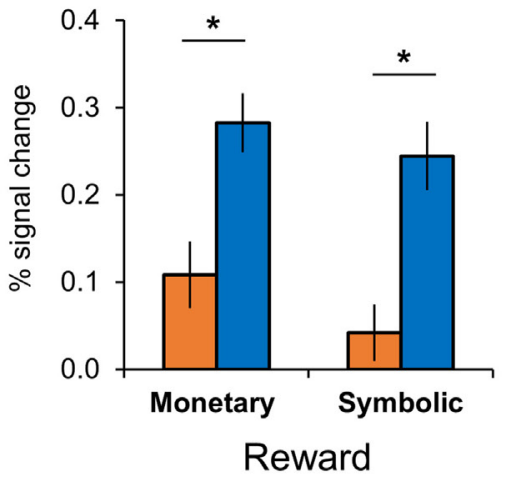

B

\section{Group x reward-type interaction}
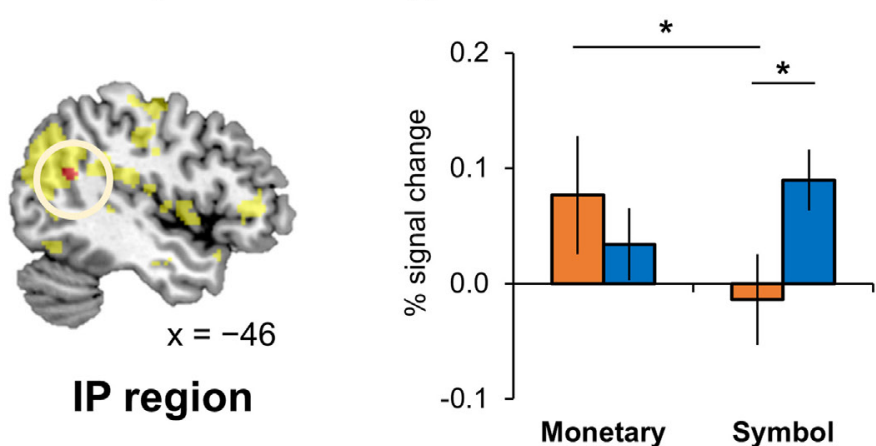

\section{$\square$ IGO group $\square$ Control group}

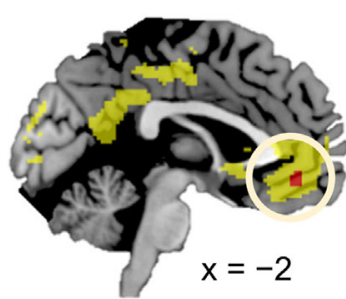
mOFC/vmPFC

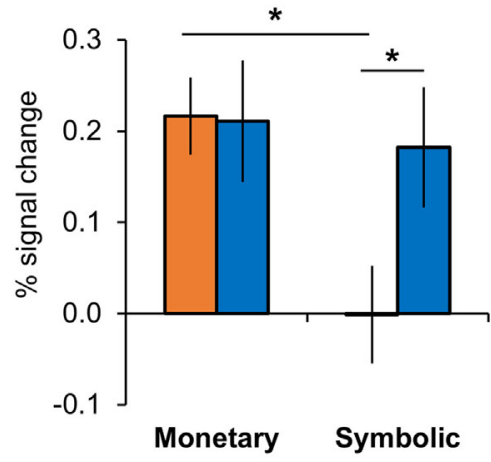

Reward

FIGURE 3 | Internet game overuse (IGO) associated differences in brain activations during reward processing. (A) The IGO group showed reduced activations for reward in the left rostral anterior cingulate cortex/ventromedial prefrontal cortex (rACC/vmPFC) region (shown in green) indicated by a significant group main effect $\left[\mathrm{IGO}_{\text {(monetary reward + symbolic reward) }} \mathrm{VS}\right.$. Control (monetary reward + symbolic reward)]. (B) The left inferior parietal (IP) region and medial orbitofrontal cortex/ventromedial prefrontal cortex (mOFC/vmPFC) showing a significant interaction effect between group and reward types (shown in red) $\left[\left(\mathrm{IGO}_{\text {monetary reward }}>\mathrm{IGO}_{\text {symbolic reward }}\right) \mathrm{Vs}_{\text {. }}\right.$

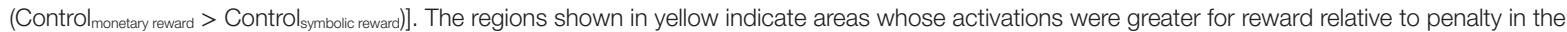
voxel-wise analysis of all participants.

\section{Group Differences in Brain Responses to Reward}

According to the two-way factorial ANOVA analysis with the factors group (IGO vs. Control) and positive feedback type (monetary reward vs. symbol reward) (Table 2; Table S4 in
Supplementary Material), an anterior dorsal part of vmPFC near the rostral anterior cingulate cortex ( $\mathrm{rACC} / \mathrm{vmPFC}$ ) was the only brain region showing a significant reduction of activation of IGO relative to the Control group (Figure 3A, cluster-level FWE 
$p<0.05)$. Furthermore, we found a significant group and feedback interaction in the more posterior ventral part of vmPFC near the medial orbitofrontal cortex ( $\mathrm{mOFC} / \mathrm{vmPFC})$ and the left inferior parietal (IP) region, in which the IGO group showed reduced activation for symbolic relative to monetary reward, whereas the Control group showed no such reward type difference (Figure 3B, cluster-level FWE $p<0.05$ ).

In particular, for the neutral condition (IGO: $r=0.54, p<0.05$; Control: $r=0.21, p=0.38$ ), for which no monetary incentive or loss was involved in learning, only in the IGO group was the individual difference in the level of activity in the $\mathrm{mOFC} / \mathrm{vmPFC}$ region significantly positively correlated with the CR (Figure 4). A trend of positive correlation was found in the IGO group also with the correct-stay rate (following the symbolic reward) of the neutral condition (IGO: $r=0.47, p=0.051$; Control: $r=0.32$, $p=0.17)$. These findings are in contrast to the observation that the level of mOFC/vmPFC activity in IGO group individuals had no relationship with the incorrect-change rate of the neutral condition $(r=0.30, p=0.23)$. For the IGO group, no such relationship was observed in the $\mathrm{rACC} / \mathrm{vmPFC}$ region that was defined by a significant group difference (IGO: monetary,

TABLE 2 | Brain regions showing group differences in response to reward.

\begin{tabular}{|c|c|c|c|c|c|c|c|}
\hline \multirow[t]{2}{*}{ Region } & \multirow[t]{2}{*}{ R/L/M } & \multirow[t]{2}{*}{ BA } & \multicolumn{3}{|c|}{ MNI coordinate } & \multicolumn{2}{|c|}{ Stats } \\
\hline & & & $x$ & $y$ & $z$ & $T$ & Size $^{a}$ \\
\hline \multicolumn{8}{|c|}{ Group difference } \\
\hline \multicolumn{8}{|c|}{ IGO $<$ Control } \\
\hline rACC/vmPFC & $\mathrm{L}$ & 32 & -6 & 50 & 12 & 18.8 & 29 \\
\hline \multicolumn{6}{|l|}{ IGO > Control } & NS & \\
\hline \multicolumn{8}{|c|}{ Group $\times$ reward-type interaction } \\
\hline IP region & L & 39 & -46 & -56 & 20 & 20.5 & 26 \\
\hline $\mathrm{mOFC} / \mathrm{vmPFC}$ & M & 11 & -2 & 44 & -10 & 19.8 & 24 \\
\hline
\end{tabular}

Inclusively masked with contrast of [reward-penalty].

IGO group, Internet game overuse group; IP region, inferior parietal region;

rACC, rostral anterior cingulate cortex; MOFC, medial orbitofrontal cortex; vmPFC,

ventromedial prefrontal cortex.

${ }^{a}$ Cluster-level corrected $p<0.05$. $r=-0.13 p=0.62$; symbol, $r=0.13 p=0.61$; Control: monetary, $r=-0.23, p=0.34$; symbol, $r=-0.17, p=0.47$ ) or the IP region defined by a significant group by feedback type interaction (IGO: monetary, $r=0.12 p=0.65$; symbol, $r=0.31 p=0.22$; Control: monetary, $r=-0.26, p=0.27$; symbol, $r=-0.22, p=0.36$ ).

\section{Group Differences in Brain Responses to Penalty}

There were no IGO-associated differences in brain response for penalty: there was no group difference or interaction between group and feedback type (cluster-level FWE $p<0.05$ ). However, the penalty type itself (monetary penalty vs. symbolic penalty) affected brain responses in several regions, as listed in Table S5 in Supplementary Material.

\section{The Relationship between Incentive-Related VS Responses and Severity of IGO Symptoms}

In a VS region defined a priori based on a previous finding for gambling disorder (19), a significant positive relationship was found in the IGO group between the IAT score and the size of the incentive effect of the regional activity (monetary reward $>$ symbolic reward) (MNI $x, y, z=12,20,-2, k=22, T=5.65$, small volume corrected FWE $p<0.05 ; r=0.87, p<0.001)$, but not the Control group $(r=-0.02, p=0.87)$ (Figure 5). Similar results were found with IGADS scores (IGO: $r=0.71 p<0.001$; Control: $r=-0.24, p=0.31)$. This relationship was also confirmed with the IGADS score for the right VS (MNI $x, y, z=12,14,0, k=12$, $T=4.7$, small volume corrected FWE $p<0.05)$. Other brain regions showing the same relationship either with IAT or IGADS are reported in Table S6 in Supplementary Material.

\section{DISCUSSION}

Here we investigated whether and how behavioral performance and feedback-related neural responses during learning are altered in IGO group. Our main interest was to see if IGO is associated with abnormally high sensitivity for motivational salient feedback, or abnormally low sensitivity for non-salient feedback. Within a simple association learning task, participants
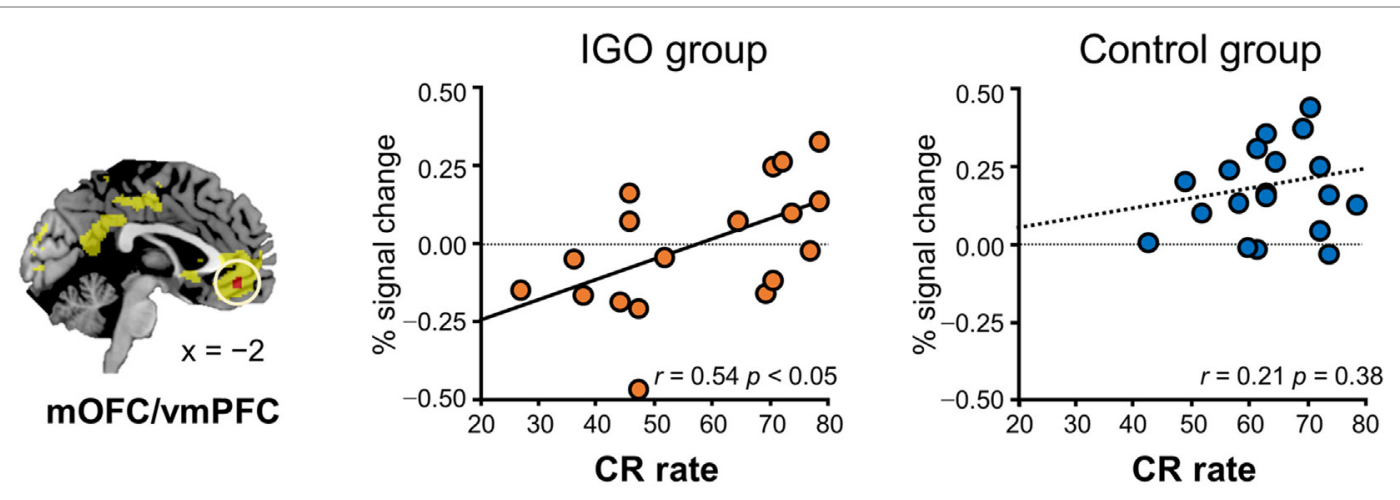

FIGURE 4 | Relationship between level of medial orbitofrontal cortex/ventromedial prefrontal cortex (mOFC/vmPFC) response for symbolic reward and learning. Only for the Internet game overuse (IGO) group, the percent correct response (CR) rate of the neutral condition was positively correlated with the level of brain response for symbolic reward. The regions shown in yellow indicate areas whose activations were greater for reward relative to penalty in the voxel-wise analysis of all participants. 


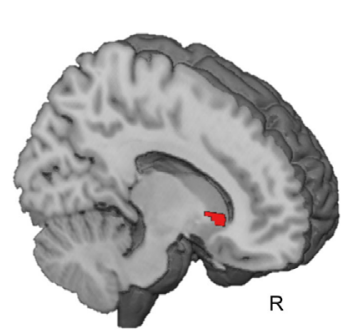

ventral striatum

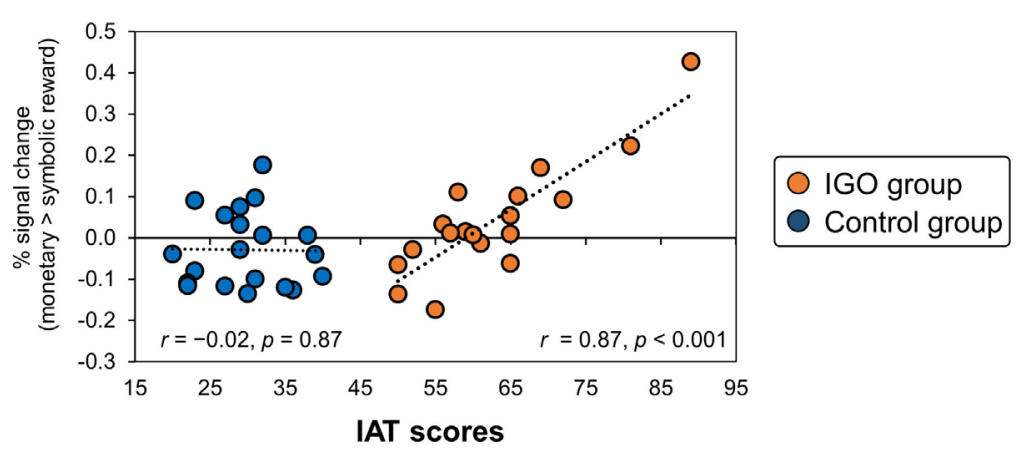

FIGURE 5 | The relationship between ventral striatum (VS) response bias for monetary reward and severity of Internet game overuse (IGO) symptoms. The greater differential activation in the right VS region for monetary relative to symbolic reward [for the contrast of (monetary reward > symbolic reward)] was associated with higher IAT scores in the IGO group, but not the Control group. IAT: Young's internet addiction test.

experienced various types of feedback that differed in motivational saliency (i.e., monetary reward/penalty vs. non-monetary symbolic reward/penalty). In comparison to the Control group, we observed several behavioral and neural response differences in the IGO group. First, individuals with IGO exhibited reduced learning efficiency for non-monetary (i.e., symbolic) positive feedback, whereas they did not differ in learning from monetarypositive feedback or from negative feedback (i.e., monetary or symbolic penalty). Second, the brain response for symbolic reward was blunted in the vmPFC region, unlike for monetary reward. Lastly, the level of bias observed in the VS activation for monetary reward, relative to symbolic reward, was associated with severity of IGO symptoms.

\section{Internet Gaming Overuse and Learning Efficiency}

It is well-known that monetary incentives improve performance (44-46). This incentive effect was clearly observed for learning in the current study, where the CR of the gain condition was greater than that of the loss or neutral condition across all participants of both groups. However, the learning impairment with symbolic reward, but not monetary reward, was detected in the IGO group only when the effect of positive feedback was distinguished from that of negative feedback. This is contrast to the absence of a group difference in the incorrect-change rate, indicating that the IGO group had no problem in error processing from negative feedback, whether monetary or symbolic. Given that symbolic reward provides as much learning-relevant information as monetary reward, indicating the previously chosen response as the target response, the internal motivation derived from the symbolic reward seems to have been greater for individuals without IGO than for those with IGO. For the Control group, both types of positive feedback were equally useful for repeating the same response in the future. These findings can be viewed as consistent with "incentive sensitivity hypothesis," since individuals with IGO did not process symbolic as efficiently as monetary reward, either due to impaired learning or reduced motivation. If they failed to attend or encode an event followed by the lesser motivationally salient feedback (i.e., symbolic reward), then the individuals with
IGO may have not often been able to repeat the same response in the subsequent trial. At the least, the current study indicates that this is not associated with their inability to process symbolic/ social feedback, since the IGO individuals successfully avoided repeating the same error response after symbolic penalty as often as after monetary penalty.

To further understand how the IGO group performed as well as the Control group in terms of correct-stay rate following monetary reward, we examined the relationship between individual differences in efficiency of reward processing and other psychological measures and found this to be associated with WM capacity, but only for the IGO group, and only for monetary reward. It is reasonable to suppose that WM individual differences will influence performance when a WM strategy is employed. The positive correlation between WM and the learning performance for monetary feedbacks in the IGO group suggests the use of a WM strategy when high motivation is triggered by monetary incentive. We also observed a similar relationship for monetary penalty in the IGOs, suggesting higher motivation IGO individuals, for both monetary incentive and loss. The self-reported arousal data are consistent with this conclusion. The difference in arousal levels for the two feedback types (monetary > symbolic), was significantly greater in the IGO group than the Controls (more so for penalty than reward). Given that high arousal associated with stronger motivation is known to improve performance (47, 48), the greater arousal measured by self-report in the current study indicates that unlike the Controls, the IGO group had greater motivation for monetary feedback relative to the symbolic feedback, which resulted in recruiting a WM strategy.

\section{Reduced Activation for Positive Feedback Processing: rACC/vmPFC}

The $\mathrm{rACC} / \mathrm{vmPFC}$ is known to be anatomically connected with the striatum and associated with reward processing (49). It is viewed as a part of a reward circuit $(50,51)$ that is sensitive to feedback valence (positive $>$ negative) $(52,53)$. In the current study, reduced responses of $\mathrm{rACC} / \mathrm{vmPFC}$ were found in the IGO group, both for monetary and symbolic rewards. Recent imaging studies of IGD revealed reductions in glucose metabolism (54) 
and gray matter volume (55) in the $\mathrm{rACC} / \mathrm{vmPFC}$ region. The reduction of reward-associated activations has been well documented in individuals with substance addiction, such as cocaine addiction (56), as well as its correlation with the level of substance pursuit behavior (57). The current findings suggest that impaired reward processing is associated with IGO, which shares neuropathologies with other types of addiction, including substance abuse. We speculate that the probable impairments of reward processing by $\mathrm{rACC} / \mathrm{vmPFC}$ must have been compensated for with a cognitive strategy, such as WM, as described above, when a monetary incentive was at stake.

\section{Reduced Activations for Symbolic Reward: OFC/vmPFC and IP Region}

Both in the $\mathrm{mOFC} / \mathrm{vmPFC}$ and IP regions, reduced activations specific for symbolic reward were observed only in the IGO group. These patterns of differential activation were in parallel with the behavioral data. For example, the correct-stay rate, especially following symbolic reward, was lower in the IGO group. The vmPFC region near the medial OFC has been suggested to be involved in value representation (58-60), especially for the subjective value of reward (e.g., reward magnitude) $(31,61)$ or preference information $(62)$. Therefore, the reduced activations for the symbolic reward relative to the monetary reward in the $\mathrm{mOFC} / \mathrm{vmPFC}$ of IGOs may reflect lower value representation for the non-monetary feedback, resulting in a weak motivational modification in goal-directed behavior $(60,63)$. This is in contrast to the Controls, who did not show any significant differences in activation or behavioral performance between two types of reward, suggesting that the symbolic feedback was comparable to the monetary incentive in terms of reward value as positive feedback. This interpretation is relevant to a well-known clinical feature of addiction, namely, losing interest in social and recreational activities other than the addicted behavior, such as hobbies and entertainment (e.g., Internet gaming) (64). For monetary reward, we did not find any difference in brain activations of these regions between the IGO and Control groups, in contrast to the findings of Dong et al. (7), who reported an increased OFC activation for monetary reward in individuals with IGO, relative to Controls.

It is worth noting that we found group differences in rewardassociated activations in two focal regions of vmPFC: the more dorsal anterior region referred as $\mathrm{rACC} / \mathrm{vmPFC}$ and the more ventral posterior region called $\mathrm{mOFC} / \mathrm{vmPFC}$. In contrast to decreases in activation in the dorsal anterior region of vmPFC (rACC/vmPFC) for both types of reward, in the more ventral posterior region ( $\mathrm{mOFC} / \mathrm{vmPFC}$ ) the IGO-associated reduction was found only for symbolic reward. A functional dissociation has been suggested by a recent neuroimaging study (50): the more dorsal part of vmPFC (corresponding the rACC/vmPFC in our study) for positive prediction error; the more ventral part of vmPFC (mOFC/vmPFC in our study) for value processing. According to this dissociation, IGO seems to be associated not only with impairment of positive prediction error processing (rACC/vmPFC), which should be required for all reward type, but also with impairment of value processing (mOFC/vmPFC), which affects only for the non-monetary reward.

Like the vmPFC, reduced activation for the symbolic relative to monetary reward was found in the left IP region of the IGO group, whereas there was no reward type difference in the Control group. Activity of the IP region is known to be involved in directing attention (65) or reward-related decision making as a part of cognitive control (66). The IP activation level has been shown to be modulated by motivation $(67,68)$ or reward $(69)$. Therefore, the reduced response for symbolic reward, relative to monetary reward, in the IP region of IGO group can be interpreted as a lower level of attentional control for symbolic reward, resulting in poorer learning in these individuals.

Note that no relationship was found in the IP region between individual differences in the activation level for symbolic reward and the $\mathrm{CR}$ rate of the neutral condition in the IGO group, unlike the $\mathrm{mOFC} / \mathrm{vmPFC}$ region. This might be related to a characteristic of our task, in which the behavioral adjustments for next response involved long-term delayed period across many trials. Unlike the value processing of the $\mathrm{mOFC/vmPFC}$ region, the attentional processing mediated by the IP region may not be long lasting across inter-trials during learning, at least not long enough to translate into the average learning performance. The representations of reward encoded by the mOFC/vmPFC $(31,59)$, on the contrary, have been shown to involve a long-term motivational setup of the individual (70). This may explain our finding of an association between individual differences at the neural level of the mOFC/vmPFC and average performance level. The absence of such a relationship in our Control group may be related to the very small inter-individual variations of behavioral performance in this group, due to the high (above 90\%) average correct-stay rate for symbolic reward (as well as for monetary reward in both groups). Thus, we could not determine if there was a relationship between behavioral performance and mOFC/ vmPFC activation for monetary reward in either group, or for symbolic reward in the Control group.

\section{Incentive Effects in the VS Associated with Severity of IGO Symptoms}

As predicted, individual differences in VS bias for monetary reward were directly related to IGO severity. This finding is similar to that from pathological gamblers, in whom the differential VS activation for monetary reward relative to a non-addictive reward (i.e., an erotic reward) was associated with gambling severity (19). In summary, our results for IGOs support the notion that addiction is associated not with increased sensitivity (e.g., greater VS activation to all addiction-related stimuli relative to normal healthy individuals), but with an imbalance of sensitivity (i.e., greater VS activation for the addiction-related stimulus relative to non-addictive stimuli) $(15,19)$.

Note that VS biases were, in fact, observed in both groups: some showed a bias toward monetary reward and others toward symbolic feedback (shown in Figure 5). Unlike the $\mathrm{mOFC} / \mathrm{vmPFC}$, the VS bias toward monetary relative to symbolic reward was not exclusively observed in the IGO group. In addition, half of the IGO group (as well as half of Controls) 
showed a VS bias in the opposite direction, i.e., a greater response toward symbolic, rather than monetary reward. The greater bias toward monetary relative to symbolic reward in individuals with severe IGO symptoms suggests that this could be a risk factor for IGD.

\section{Penalty Processing in Individuals with IGO}

Unlike the case for reward processing, we did not find any behavioral or neuronal evidence in individuals with IGO of impaired penalty processing. This may seem surprising in light of past findings. For example, it has been reported that IGD individuals show reduced insular brain activation accompanying response inhibition difficulties (30), or hyperactivation of the ACC during error processing (8), results that are consistent with those from substance use disorder individuals, who showed impaired response inhibition or error processing (71). One possibility for the discrepancy between these and our results is the nature of error processing following penalty. The efficient penalty feedback processing in our study, measured as incorrect-change rate, is not associated with how well one inhibits a previously punished response, but is related to how well one switches to another response choice (three options) after penalty. Another possibility is that penalty feedback processing, even including response inhibition and error processing, may not be affected or impaired in individuals at high risk for IGD.

\section{Limitations}

We did not find any IGO-related hypersensitivity for monetary reward, except for an indication of using a WM strategy. We cannot rule out the possibility that hypersensitivity would have been observed if a sufficiently larger incentive was used than $20 \%$ of the accumulated earning of $500 \mathrm{KRW}$ (less than 0.5 USD), like the 10 USD used by Dong et al. (7), or the video gaming items used by King and Delfabbro (28). However, we had no problem in finding differential responses for a specific reward type in the IGO group, both in brain activations and in behavior. Due to the practical difficulty in separating the effects of IGD from other personality issues, we cannot exclude the possibility that the high level of depression and impulsivity associated with abnormal reward processing $(72,73)$ influenced our results. Note that we focused on feedback-related brain activity using a fixed contingency between a stimulus and a type of positive (or negative) feedback. This classical learning paradigm was methodologically useful for measuring the level of learning-related behavioral performance. However, this deterministic reward paradigm did not afford the opportunity to observe abnormal reward-anticipatory processing in the Internet gamer (25). Lastly, the current findings were obtained from individuals with IGO who were identified via screening with the criteria of Young' IAT, which has been the dominant screening method in previous research. In future research, the methodological procedures might be improved $(74,75)$ using a more reliable and valid tool, such as the DSM-5 criteria (76).

\section{CONCLUSION}

In summary, IGOs was found to impair selectively learning from non-incentive symbolic reward, while not induced the normal level of brain responses in the $\mathrm{mOFC} / \mathrm{vmPFC}$ and IP regions, indicating deficits in reward evaluation and attentional control processing, respectively. Also, the level of bias in the VS response toward monetary reward was associated with addiction severity, indicating a risk factor for IGD. These results provide clues for effective treatment and prevention of IGD. Considering formal educational settings where symbolic rewards are used rather than monetary reward, they suggest that individuals with IGO would suffer from poor learning performance in class, in addition to not allocating enough study time outside of school. The same problem would reoccur in normal daily life, where goal-directed behavior is often driven by internal motivation, not by external incentives. In particular, for individuals who combine a greater VS bias for external incentive (e.g., monetary reward) relative to internal incentive (e.g., symbolic feedback), with a personality of high depression and/or impulsivity, Internet games should be approached with great caution and care, rather than sought out as harmless entertainment.

\section{ETHICS STATEMENT}

The study was carried out in accordance with the recommendations of the principles of Declaration of Helsinki, with written informed consent obtained from all subjects. The protocol was approved by the institutional review board of Kangwon National University.

\section{AUTHOR CONTRIBUTIONS}

JK, HK, and EK made substantial contributions to the conception and design of this work. JK recruited the subjects and collected and analyzed the fMRI data. All authors contributed to the interpretation of data. JK and EK drafted the manuscript, which all authors critically revised for important intellectual content. All authors approved the final version of the manuscript.

\section{ACKNOWLEDGMENTS}

This work was supported by the Brain Research Program of the National Research Foundation of Korea, Ministry of Science and ICT (NRF-2006-2005112). We thank Hee-Youn Cho and Hojin Jeong for assistance in conducting fMRI scanning.

\section{SUPPLEMENTARY MATERIAL}

The Supplementary Material for this article can be found online at http://journal.frontiersin.org/article/10.3389/fpsyt.2017.00195/ full\#supplementary-material. 


\section{REFERENCES}

1. Kuss DJ. Internet gaming addiction: current perspectives. Psychol Res Behav Manag (2013) 6:125. doi:10.2147/PRBM.S39476

2. Johansson A, Götestam KG. Problems with computer games without monetary reward: similarity to pathological gambling. Psychol Rep (2004) 95(2): 641-50. doi:10.2466/PR0.95.6.641-650

3. Koob GF, Volkow ND. Neurocircuitry of addiction. Neuropsychopharmacology (2010) 35(1):217-38. doi:10.1038/npp.2010.4

4. Kelley AE, Berridge KC. The neuroscience of natural rewards: relevance to addictive drugs. J Neurosci (2002) 22(9):3306-11.

5. Strickland JC, Bolin BL, Lile JA, Rush CR, Stoops WW. Differential sensitivity to learning from positive and negative outcomes in cocaine users. Drug Alcohol Depend (2016) 166:61-8. doi:10.1016/j.drugalcdep.2016.06.022

6. Ersche KD, Gillan CM, Jones PS, Williams GB, Ward LHE, Luijten M, et al. Carrots and sticks fail to change behavior in cocaine addiction. Science (2016) 352(6292):1468-71. doi:10.1126/science.aaf3700

7. Dong G, Huang J, Du X. Enhanced reward sensitivity and decreased loss sensitivity in Internet addicts: an fMRI study during a guessing task. J Psychiatr Res (2011) 45(11):1525-9. doi:10.1016/j.jpsychires.2011.06.017

8. Dong G, Shen Y, Huang J, Du X. Impaired error-monitoring function in people with internet addiction disorder: an event-related FMRI study. Eur Addict Res (2013) 19(5):269-75. doi:10.1159/000346783

9. Yau YHC, Potenza MN, Mayes LC, Crowley MJ. Blunted feedback processing during risk-taking in adolescents with features of problematic Internet use. Addict Behav (2015) 45(0):156-63. doi:10.1016/j.addbeh.2015.01.008

10. Ikemoto S, Panksepp J. The role of nucleus accumbens dopamine in motivated behavior: a unifying interpretation with special reference to rewardseeking. Brain Res Brain Res Rev (1999) 31(1):6-41. doi:10.1016/S01650173(99)00023-5

11. Schultz W, Dayan P, Montague PR. A neural substrate of prediction and reward. Science (1997) 275(5306):1593-9. doi:10.1126/science.275.5306.1593

12. Flagel SB, Clark JJ, Robinson TE, Mayo L, Czuj A, Willuhn I, et al. A selective role for dopamine in stimulus-reward learning. Nature (2011) 469(7328):53-7. doi:10.1038/nature09588

13. Frank MJ, Seeberger LC, O'Reilly RC. By carrot or by stick: cognitive reinforcement learning in parkinsonism. Science (2004) 306(5703):1940-3. doi:10.1126/science.1102941

14. Myers CE, Sheynin J, Balsdon T, Luzardo A, Beck KD, Hogarth L, et al. Probabilistic reward-and punishment-based learning in opioid addiction: experimental and computational data. Behav Brain Res (2016) 296:240-8. doi:10.1016/j.bbr.2015.09.018

15. Bühler M, Vollstädt-Klein S, Kobiella A, Budde H, Reed LJ, Braus DF, et al. Nicotine dependence is characterized by disordered reward processing in a network driving motivation. Biol Psychiatry (2010) 67(8):745-52. doi:10.1016/ j.biopsych.2009.10.029

16. Goldstein RZ, Tomasi D, Alia-Klein N, Carrillo JH, Maloney T, Woicik PA, et al. Dopaminergic response to drug words in cocaine addiction. J Neurosci (2009) 29(18):6001-6. doi:10.1523/JNEUROSCI.4247-08.2009

17. Dong G, Hu Y, Lin X. Reward/punishment sensitivities among internet addicts: implications for their addictive behaviors. Prog Neuropsychopharmacol Biol Psychiatry (2013) 46:139-45. doi:10.1016/j.pnpbp.2013.07.007

18. Tanabe J, Thompson L, Claus E, Dalwani M, Hutchison K, Banich MT. Prefrontal cortex activity is reduced in gambling and nongambling substance users during decision-making. Hum Brain Mapp (2007) 28(12):1276-86. doi:10.1002/hbm.20344

19. Sescousse G, Barbalat G, Domenech P, Dreher J-C. Imbalance in the sensitivity to different types of rewards in pathological gambling. Brain (2013) 136(8):2527-38. doi:10.1093/brain/awt126

20. Robinson TE, Berridge KC. The neural basis of drug craving: an incentivesensitization theory of addiction. Brain Res Rev (1993) 18(3):247-91. doi:10.1016/0165-0173(93)90013-P

21. Volkow ND, Wang G-J, Fowler JS, Thanos P, Logan J, Gatley SJ, et al. Brain DA D2 receptors predict reinforcing effects of stimulants in humans: replication study. Synapse (2002) 46(2):79-82. doi:10.1002/syn.10137

22. Blum K, Braverman ER, Holder JM, Lubar JF, Monastra VJ, Miller D, et al. The reward deficiency syndrome: a biogenetic model for the diagnosis and treatment of impulsive, addictive and compulsive behaviors. J Psychoactive Drugs (2000) 32(Suppl 1):1-112. doi:10.1080/02791072.2000.10736099
23. Hou H, Jia S, Hu S, Fan R, Sun W, Sun T, et al. Reduced striatal dopamine transporters in people with internet addiction disorder. J Biomed Biotechnol (2012) 2012:854524. doi:10.1155/2012/854524

24. Kim SH, Baik S-H, Park CS, Kim SJ, Choi SW, Kim SE. Reduced striatal dopamine D2 receptors in people with Internet addiction. Neuroreport (2011) 22(8):407-11. doi:10.1097/WNR.0b013e328346e16e

25. Hahn T, Notebaert KH, Dresler T, Kowarsch L, Reif A, Fallgatter AJ. Linking online gaming and addictive behavior: converging evidence for a general reward deficiency in frequent online gamers. Front Behav Neurosci (2014) 8:385. doi:10.3389/fnbeh.2014.00385

26. Kim JE, Son JW, Choi WH, Kim YR, Oh JH, Lee S, et al. Neural responses to various rewards and feedback in the brains of adolescent Internet addicts detected by functional magnetic resonance imaging. Psychiatry Clin Neurosci (2014) 68:463-70. doi:10.1111/pcn.12154

27. Jeong EJ, Kim DH. Social activities, self-efficacy, game attitudes, and game addiction. Cyberpsychol Behav Soc Netw (2011) 14(4):213-21. doi:10.1089/ cyber.2009.0289

28. King DL, Delfabbro PH. The cognitive psychology of Internet gaming disorder. Clin Psychol Rev (2014) 34(4):298-308. doi:10.1016/j.cpr.2014. 03.006

29. Wrase J, Kahnt T, Schlagenhauf F, Beck A, Cohen MX, Knutson B, et al. Different neural systems adjust motor behavior in response to reward and punishment. Neuroimage (2007) 36(4):1253-62. doi:10.1016/j.neuroimage. 2007.04.001

30. Ko C-H, Hsieh T-J, Chen C-Y, Yen C-F, Chen C-S, Yen J-Y, et al. Altered brain activation during response inhibition and error processing in subjects with Internet gaming disorder: a functional magnetic imaging study. Eur Arch Psychiatry Clin Neurosci (2014) 264(8):661-72. doi:10.1007/s00406013-0483-3

31. O'Doherty J, Kringelbach ML, Rolls ET, Hornak J, Andrews C. Abstract reward and punishment representations in the human orbitofrontal cortex. Nat Neurosci (2001) 4(1):95-102. doi:10.1038/82959

32. Breiter HC, Aharon I, Kahneman D, Dale A, Shizgal P. Functional imaging of neural responses to expectancy and experience of monetary gains and losses. Neuron (2001) 30(2):619-39. doi:10.1016/S0896-6273(01)00303-8

33. Lee HC, Ahn CY. Development of the Internet game addiction diagnostic scale. Korean J Health Psychol (2002) 7(2):211-39.

34. Young KS, Rogers RC. The relationship between depression and Internet addiction. Cyberpsychol Behav (1998) 1(1):25-8. doi:10.1089/cpb.1998.1.25

35. Kim EJ, Lee SY, Oh SG. The validation of Korean adolescent Internet addiction scale (K-AIAS). Korean J Clin Psychol (2003) 22(1):125-39.

36. Young KS. Psychology of computer use: XL. Addictive use of the Internet: a case that breaks the stereotype. Psychol Rep (1996) 79(3):899-902. doi:10.2466/ pr0.1996.79.3.899

37. Kuss DJ, Griffiths MD. Internet gaming addiction: a systematic review of empirical research. Int J Ment Health Addict (2012) 10(2):278-96. doi:10.1007/ s11469-011-9318-5

38. BeckAT. Depression: Clinical, Experimental, and Theoretical Aspects. Philadelphia: University of Pennsylvania Press (1967).

39. Lee S-R, Lee W-H, Park J-S, Kim S-M, Kim J-W, Shim J-H. The study on reliability and validity of Korean version of the barratt impulsiveness scale11-revised in nonclinical adult subjects. J Korean Neuropsychiatr Assoc (2012) 51(6):378-86. doi:10.4306/jknpa.2012.51.6.378

40. Cloninger CR, Svrakic DM, Przybeck TR. A psychobiological model of temperament and character. Arch Gen Psychiatry (1993) 50(12):975-90. doi:10.1001/archpsyc.1993.01820240059008

41. Wechsler D. Wechsler Adult Intelligence Scale. 4th ed. (Vol. 22). San Antonio, TX: NCS Pearson (2008). 498 p. (WAIS-IV).

42. Lang PJ. Behavioral treatment and bio-behavioral assessment: computer applications. In: Sidowski JB, Johnson JH, Williams TA, editors. Technology in Mental Health Care Delivery Systems. Norwood, NJ: Ablex (1980). p. 119-37.

43. Power JD, Barnes KA, Snyder AZ, Schlaggar BL, Petersen SE. Spurious but systematic correlations in functional connectivity MRI networks arise from subject motion. Neuroimage (2012) 59(3):2142-54. doi:10.1016/j.neuroimage. 2011.10.018

44. Wu Y, Zhou X. The P300 and reward valence, magnitude, and expectancy in outcome evaluation. Brain Res (2009) 1286:114-22. doi:10.1016/j.brainres. 2009.06.032 
45. Bonner SE, Sprinkle GB. The effects of monetary incentives on effort and task performance: theories, evidence, and a framework for research. Account Org Soc (2002) 27(4):303-45. doi:10.1016/S0361-3682(01)00052-6

46. Martin B. Reward and punishment associated with the same goal response: a factor in the learning of motives. Psychol Bull (1963) 60:441-51. doi:10.1037/ h0045000

47. Cuthbert BN, Schupp HT, Bradley MM, Birbaumer N, Lang PJ. Brain potentials in affective picture processing: covariation with autonomic arousal and affective report. Biol Psychol (2000) 52(2):95-111. doi:10.1016/S03010511(99)00044-7

48. Lang PJ, Bradley MM, Cuthbert BN. Motivated attention: affect, activation, and action. In: Lang PJ, Simons RF, Balaban MT, editors. Attention and Orienting: Sensory and Motivational Processes. Hillsdale, NJ: Lawrence Erlbaum Associates (1997). p. 97-135.

49. Baleydier C, Mauguiere F. The duality of the cingulate gyrus in monkey. Neuroanatomical study and functional hypothesis. Brain (1980) 103(3):525-54. doi:10.1093/brain/103.3.525

50. Vassena E, Krebs RM, Silvetti M, Fias W, Verguts T. Dissociating contributions of ACC and vmPFC in reward prediction, outcome, and choice. Neuropsychologia (2014) 59:112-23. doi:10.1016/j.neuropsychologia.2014.04.019

51. Amiez C, Joseph J-P, Procyk E. Reward encoding in the monkey anterior cingulate cortex. Cereb Cortex (2006) 16(7):1040-55. doi:10.1093/cercor/bhj046

52. Mies GW, van der Molen MW, Smits M, Hengeveld MW, van der Veen FM. The anterior cingulate cortex responds differently to the validity and valence of feedback in a time-estimation task. Neuroimage (2011) 56(4):2321-8. doi:10.1016/j.neuroimage.2011.04.015

53. Nieuwenhuis S, Slagter HA, von Geusau NJ, Heslenfeld DJ, Holroyd CB. Knowing good from bad: differential activation of human cortical areas by positive and negative outcomes. Eur J Neurosci (2005) 21(11):3161-8. doi:10.1111/j.1460-9568.2005.04152.x

54. Tian M, Chen Q, Zhang Y, Du F, Hou H, Chao F, et al. PET imaging reveals brain functional changes in Internet gaming disorder. Eur J Nucl Med Mol Imaging (2014) 41(7):1388-97. doi:10.1007/s00259-014-2708-8

55. Wang H, Jin C, Yuan K, Shakir TM, Mao C, Niu X, et al. The alteration of gray matter volume and cognitive control in adolescents with Internet gaming disorder. Front Behav Neurosci (2015) 9:64. doi:10.3389/fnbeh.2015.00064

56. Goldstein RZ, Alia-Klein N, Tomasi D, Carrillo JH, Maloney T, Woicik PA, et al. Anterior cingulate cortex hypoactivations to an emotionally salient task in cocaine addiction. Proc Natl Acad Sci U S A (2009) 106(23):9453-8. doi:10.1073/pnas.0900491106

57. Volkow ND, Wang G-J, Tomasi D, Baler RD. Unbalanced neuronal circuits in addiction. Curr Opin Neurobiol (2013) 23(4):639-48. doi:10.1016/j.conb. 2013.01.002

58. Rangel A, Camerer C, Montague PR. A framework for studying the neurobiology of value-based decision making. Nat Rev Neurosci (2008) 9(7):545-56. doi:10.1038/nrn2357

59. Kringelbach ML, Rolls ET. The functional neuroanatomy of the human orbitofrontal cortex: evidence from neuroimaging and neuropsychology. Prog Neurobiol (2004) 72(5):341-72. doi:10.1016/j.pneurobio.2004.03.006

60. Hare TA, Camerer CF, Rangel A. Self-control in decision-making involves modulation of the vmPFC valuation system. Science (2009) 324(5927):646-8. doi:10.1126/science.1168450

61. Wang Q, Luo S, Monterosso J, Zhang J, Fang X, Dong Q, et al. Distributed value representation in the medial prefrontal cortex during intertemporal choices. J Neurosci (2014) 34(22):7522-30. doi:10.1523/JNEUROSCI.0351-14.2014

62. Tremblay L, Schultz W. Relative reward preference in primate orbitofrontal cortex. Nature (1999) 398(6729):704-8. doi:10.1038/19525
63. Gourley SL, Zimmermann KS, Allen AG, Taylor JR. The medial orbitofrontal cortex regulates sensitivity to outcome value. J Neurosci (2016) 36(16): 4600-13. doi:10.1523/JNEUROSCI.4253-15.2016

64. Grüsser SM, Thalemann R, Griffiths MD. Excessive computer game playing: evidence for addiction and aggression? Cyberpsychol Behav (2006) 10(2): 290-2. doi:10.1089/cpb.2006.9956

65. Rushworth MF, Paus T, Sipila PK. Attention systems and the organization of the human parietal cortex. J Neurosci (2001) 21(14):5262-71.

66. Liu X, Hairston J, Schrier M, Fan J. Common and distinct networks underlying reward valence and processing stages: a meta-analysis of functional neuroimaging studies. Neurosci Biobehav Rev (2011) 35(5):1219-36. doi:10.1016/j. neubiorev.2010.12.012

67. Locke HS, Braver TS. Motivational influences on cognitive control: behavior, brain activation, and individual differences. Cogn Affect Behav Neurosci (2008) 8(1):99-112. doi:10.3758/CABN.8.1.99

68. Mohanty A, Gitelman DR, Small DM, Mesulam MM. The spatial attention network interacts with limbic and monoaminergic systems to modulate motivation-induced attention shifts. Cereb Cortex (2008) 18(11):2604-13. doi:10.1093/cercor/bhn021

69. Small DM, Gitelman D, Simmons K, Bloise SM, Parrish T, Mesulam M-M. Monetary incentives enhance processing in brain regions mediating topdown control of attention. Cereb Cortex (2005) 15(12):1855-65. doi:10.1093/ cercor/bhi063

70. Viviani R. Neural correlates of emotion regulation in the ventral prefrontal cortex and the encoding of subjective value and economic utility. Front Psychiatry (2014) 5:123. doi:10.3389/fpsyt.2014.00123

71. Fillmore MT, Rush CR. Impaired inhibitory control of behavior in chronic cocaine users. Drug Alcohol Depend (2002) 66(3):265-73. doi:10.1016/S03768716(01)00206-X

72. Eshel N, Roiser JP. Reward and punishment processing in depression. Biol Psychiatry (2010) 68(2):118-24. doi:10.1016/j.biopsych.2010.01.027

73. Plichta MM, Vasic N, Wolf RC, Lesch K-P, Brummer D, Jacob C, et al. Neural hyporesponsiveness and hyperresponsiveness during immediate and delayed reward processing in adult attention-deficit/hyperactivity disorder. Biol Psychiatry (2009) 65(1):7-14. doi:10.1016/j.biopsych.2008. 07.008

74. Ko C-H, Liu G-C, Yen J-Y. Functional imaging of internet gaming disorder. In: Montag C, Reuter M, editors. Internet Addiction. Cham: Springer (2005). p. 43-63.

75. Petry NM, Rehbein F, Ko C-H, O’Brien CP. Internet gaming disorder in the DSM-5. Curr Psychiatry Rep (2015) 17(9):72. doi:10.1007/s11920-0150610-0

76. American Psychiatric Association. Diagnostic and Statistical Manual of Mental Disorders $\left(D S M-5^{\circledast}\right)$. Washington, DC: American Psychiatric Association (2013). doi:10.1176/appi.books.9780890425596

Conflict of Interest Statement: The authors declare that the research was conducted in the absence of any commercial or financial relationships that could be construed as a potential conflict of interest.

Copyright (๑) 2017 Kim, Kim and Kang. This is an open-access article distributed under the terms of the Creative Commons Attribution License (CC BY). The use, distribution or reproduction in other forums is permitted, provided the original author(s) or licensor are credited and that the original publication in this journal is cited, in accordance with accepted academic practice. No use, distribution or reproduction is permitted which does not comply with these terms. 